\title{
Marine monitoring in Europe: is it adequate to address environmental threats and pressures?
}

\author{
Suzanne J. Painting ${ }^{1}$, Kate A. Collingridge ${ }^{1}$, Dominique Durand ${ }^{4}$, Antoine Grémare ${ }^{2}$, Veronique Créach $^{1}$, \\ Christos Arvanitidis $^{3}$, and Guillaume Bernard ${ }^{5}$ \\ ${ }^{1}$ Centre for Environment, Fisheries and Aquaculture Science (CEFAS), Lowestoft, NR33 OHT, UK \\ ${ }^{2}$ Université de Bordeaux, EPOC, UMR 5805, 33615 Pessac, France \\ ${ }^{3}$ Hellenic Centre for Marine Research, Heraklion, 71500, Greece \\ ${ }^{4}$ COVARTEC, Bergen, 5141, Norway \\ ${ }^{5}$ CNRS, EPOC, UMR 5805, 33615 Pessac, France
}

Correspondence: Suzanne J. Painting (suzanne.painting@ cefas.co.uk)

Received: 20 June 2019 - Discussion started: 11 July 2019

Revised: 2 December 2019 - Accepted: 15 December 2019 - Published: 19 February 2020

\begin{abstract}
We provide a review of the environmental threats and gaps in monitoring programmes in European coastal waters based on previous studies, an online questionnaire, and an in-depth assessment of observation scales. Our findings underpin the JERICO-NEXT ${ }^{1}$ monitoring strategy for the development and integration of coastal observatories in Europe and support JERICO-RI ${ }^{2}$ in providing high-value physical, chemical, and biological datasets for addressing key challenges at a European level. This study highlights the need for improved monitoring of environmental threats in European coastal environments.

Participants in the online questionnaire provided new insights into gaps between environmental threats and monitoring of impacts. In total, 36 national representatives, scientists, and monitoring authorities from 12 European countries (Finland, France, Germany, Greece, Ireland, Italy, Malta, Norway, Poland, Spain, Sweden, UK) completed the questionnaire, and 38 monitoring programmes were reported. The main policy drivers of monitoring were identified as the EU Water Framework Directive (WFD), the Marine Strategy Framework Directive (MSFD), Regional Seas Conventions (e.g. OSPAR), and local drivers. Although policy drivers change over time, their overall purposes remain similar. The
\end{abstract}

\footnotetext{
${ }^{1}$ JERICO-NEXT is the European H2020 project under grant agreement no. 654410 .

${ }^{2}$ JERICO-RI is the European coastal research infrastructure (RI) community built by and through JERICO-NEXT and its predecessor JERICO (Framework 7 grant agreement 49 no. 262584).
}

most commonly identified threats to the marine environment were marine litter, shipping, contaminants, organic enrichment, and fishing. Regime change was identified as a pressure by $67 \%$ of respondents. The main impacts of these pressures or threats were identified by the majority of respondents $(>70 \%)$ to be habitat loss or destruction, underwater noise, and contamination, with $60 \%$ identifying undesirable disturbance (e.g. oxygen depletion), changes in sediment and/or substrate composition, changes in community composition, harmful microorganisms, and invasive species as impacts.

Most respondents considered current monitoring of threats to be partially adequate or not adequate. The majority of responses were related to the spatial and/or temporal scales at which monitoring takes place and inadequate monitoring of particular parameters. Suggestions for improved monitoring programmes included improved design, increased monitoring effort, and better linkages with research and new technologies. Improved monitoring programmes should be fit for purpose, underpin longer-term scientific objectives which cut across policy and other drivers, and consider cumulative effects of multiple pressures.

JERICO-RI aims to fill some of the observation gaps in monitoring programmes through the development of new technologies. The science strategy for JERICO-RI will pave the way to a better integration of physical, chemical, and biological observations into an ecological process perspective. 


\section{Introduction}

Across the globe, marine monitoring networks are becoming increasingly important for the collection, dissemination, and sharing of data for improved scientific understanding, assessment of the health of marine ecosystems, and forecasting the likely impacts of environmental change and human activities (e.g. Schofield et al., 2002, 2003; Proctor and Howarth, 2008; Duarte et al., 2018; Bailey et al., 2019; Bax et al., 2019; Buck et al., 2019; Canonico et al., 2019; Davidson et al., 2019; Grand et al., 2019; Smith et al., 2019a, b). In Europe, for example, projects and infrastructures such as JERICO ${ }^{3}$, DEVOTES $^{4}$, COPERNICUS $^{5}$, EMODnet $^{6}$, EMSO ERIC ${ }^{7}$, and AtlantOS ${ }^{8}$ have played a significant role in the coordination and advancement of monitoring in coastal and offshore waters, from operational marine services to delivering data products to end users. Changing pressures (e.g. due to population growth and climate change) and changing requirements to monitor, manage, and mitigate the impacts of pressures require the ongoing review of monitoring programmes. Over the past few decades, marine monitoring has been implemented in coastal and shelf seas around Europe in response to local or regional monitoring and oceanographic research demands. However, heterogeneity in monitoring methods and approaches has limited the integration of coastal observations. Many of the observations are driven by short-term research projects, potentially limiting the sustainability of observing systems for meeting monitoring and assessment needs.

The Dobris Assessment (EEA, 1995) listed 56 broad environmental threats, 19 of which were relevant to the coastal domain. These include physical modifications (e.g. due to urban development, industry, energy production, military activities, fisheries, recreation), contamination and coastal pollution (e.g. due to wastewater disposal, chemical contaminants, marine litter), and loss of biodiversity and genetic resources. Recent EU policy drivers and Regional Seas Conventions have led to improvements in water quality in many regions (notably the Baltic Sea, North Sea, Celtic Sea, Bay of Biscay). Nonetheless, the fourth assessment of the European environment (EEA, 2008a; see also EEA, 2015a) highlighted the fact that some regions remain affected by eutrophication, destructive fishing practices, hazardous substances, oil pollution, and invasive species. Key concerns include increasing population densities, the development of built-up areas, and likely impacts of climate change on physical (e.g. temperature, currents), chemical (e.g. acidification), and bi-

\footnotetext{
${ }^{3}$ http://www.jerico-ri.eu/previous-project/jerico-fp7/ (last access: 2 December 2019)

${ }^{4}$ http://www.devotes-project.eu/ (last access: 2 December 2019)

${ }^{5}$ https://www.copernicus.eu/en (last access: 2 December 2019)

${ }^{6}$ http://www.emodnet.eu/ (last access: 2 December 2019)

${ }^{7}$ http://www.emso.eu/ (last access: 2 December 2019)

${ }^{8}$ https://www.atlantos-h2020.eu/ (last access: 2 December 2019)
}

ological (e.g. changes in growth, species composition and distribution, loss of organisms with carbonate shells) components. The lack of comparable data presents a major obstacle for assessments of Europe's regional seas, even for well-known problems such as eutrophication (EEA, 2008b; OSPAR, 2017). More and better data are needed to develop a pan-European marine protection framework that addresses environmental issues in a cost-effective way.

A number of studies have considered the suitability of monitoring programmes in Europe (e.g. Bean et al., 2017; Borja et al., 2019; DEVOTES, 20149; García-García et al., 2019; Tett et al., 2013; Zampoukos et al., 2013) for assessing good environmental status (GES) using the biodiversity suite of Marine Strategy Framework Directive (MSFD) descriptors (D): D1 (biodiversity), D2 (non-indigenous species), D4 (food webs), and D6 (sea-floor integrity). Limitations have been identified in monitoring programmes, including limitations in spatial and temporal coverage, pressures addressed, integrated monitoring (addressing more than one descriptor and/or ecosystem component simultaneously), indicators used, and data accessibility. Differences between countries highlight budgetary constraints and differing approaches to monitoring. The Baltic region has been shown to be good at addressing multiple descriptors simultaneously, while the Mediterranean has a good history of coordination between countries and making good use of citizen science. Improved compatibility of datasets (for example, through the standardization of sampling methods and quality assurance of the data) and translating research activities into monitoring (e.g. for litter and noise) have been highlighted as key challenges (EEA, 2008a; DEVOTES, 2014).

The EU JERICO-NEXT ${ }^{10}$ project addresses the challenges of observing the complex and highly variable coastal seas at a pan-European level in order to improve operational marine services and meet the requirements of key policy drivers such as EU directives. The emphasis is on providing an integrated European observing system supporting an improved understanding of the coupling between physics, biogeochemistry, and biology to take account of and address the complexity of the coastal environment. This requires the development and application of new technologies that allow for the continuous monitoring of a larger set of parameters. It also requires an a priori definition of the optimal sampling strategy over very different spatial and temporal scales to develop fit-for-purpose coherent monitoring programmes. This will enable the JERICO community to meet the overall objective of extending the EU network of coastal observations developed during JERICO-FP7. As part of the JERICONEXT project, we conducted an opinion poll of experts in

\footnotetext{
${ }^{9}$ DEVOTES is an EU FP7 project.

${ }^{10}$ JERICO-NEXT is a Horizon 2020 funded project, implementing the second phase of the European JERICO-RI research infrastructure aiming at multidisciplinary observations of coastal and shelf seas.
} 


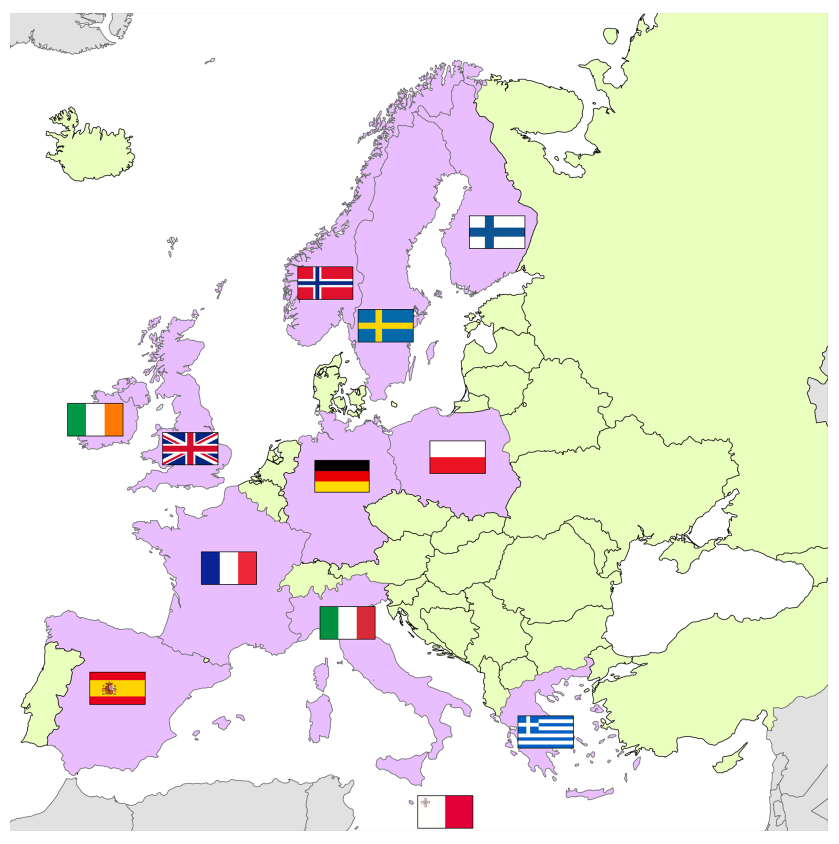

Figure 1. The countries which participated in the poll were Finland, France, Germany, Greece, Ireland, Italy, Malta, Norway, Poland, Spain, Sweden, and the UK.

European countries (Fig. 1) to identify current and emerging pressures or threats to the marine environment, identify gaps in monitoring these pressures, and contribute to a forwardlooking strategy for monitoring marine ecosystems.

\section{Methodology}

The opinion poll was designed as an online questionnaire, which could be completed over a 5-month period (29 June to 30 November 2016). The questionnaire was distributed to all partners in the JERICO-NEXT project. Partners were tasked with being national representatives and were asked to take responsibility for responding to the questionnaire and/or to collect answers from colleagues, collaborators, and responsible monitoring authorities within their countries. The national representatives were also asked to forward the questionnaire to the relevant authorities in countries which were not partners within JERICO-NEXT.

Questionnaire development was informed by a review of existing literature on environmental pressures and threats (e.g. EEA, 2008a) and the outputs of the DEVOTES project (DEVOTES, 2014). Threats to the marine environment were considered in terms of "pressures" and "impacts". Pressures were described as the human activities which have impacts on ecosystems or parts thereof (see Oesterwind et al., $2016^{11}$ ), which is compatible with the driver-pressure-

\footnotetext{
${ }^{11}$ Pressures can be described as "a result of a driver-initiated mechanism (human activity/natural process) causing an effect
}

state-impact-response (DPSIR) framework (Gabrielsen and Bosch, 2003; Elliott, 2014).

\subsection{Format of questionnaire}

The questionnaire (Fig. 2; for more detail see the Supplement Sect. S1) was developed using Google Forms and consisted of two linked forms. The first form was focussed on obtaining the views of all respondents on the environmental threats in European waters and the adequacy of current monitoring programmes. Maps were provided to ensure consistency in participant selection of "regions of interest" (see Sects. S2 and S3). For questions related to pressures and impacts, respondents could select one or more responses from lists provided. They could also add free text in order to provide detail or explanations of their responses. Questions related to the adequacy of existing monitoring programmes included comment boxes for free text to allow respondents to give their views on those monitoring programmes which were not adequate or only partly adequate for addressing environmental threats and suggestions on how to improve the monitoring of the threats identified.

The second form was focussed on national monitoring programmes, with the aim of obtaining a summary of sampling platforms used, variables measured, monitoring frequency, and the duration of the programme. This form included a section on data accessibility.

An invitation to participate in the poll and complete the questionnaire was sent to all partners in JERICO-NEXT in June 2016 and subsequently forwarded to wider contact networks. It was closed to responses in November 2016.

\subsection{Data analysis}

Once the poll was closed, responses were downloaded from Google Forms and stored in an MS Access database. Identifying information was removed from the responses to anonymize the data. More than one response was received from some countries. Results on views or opinions on environmental threats and impacts and on monitoring programmes were analysed using responses by country; i.e. categorial responses were aggregated by country, counting each response if it appeared at least once in the individual responses for the country. Marine litter, for example (see Sect. 3), was identified as a threat or pressure in all of the national responses; however, it was not identified in every single individual response for each country where there were multiple responses. The aggregated responses are referred to hereafter as "national responses".

Details of monitoring programmes and expert opinions on the adequacy of monitoring programmes were analysed for

on any part of an ecosystem that may alter the environmental state". Impacts can be defined as "consequences of environmental state change in terms of substantial environmental and/or socioeconomic effects", which can be either positive or negative. 


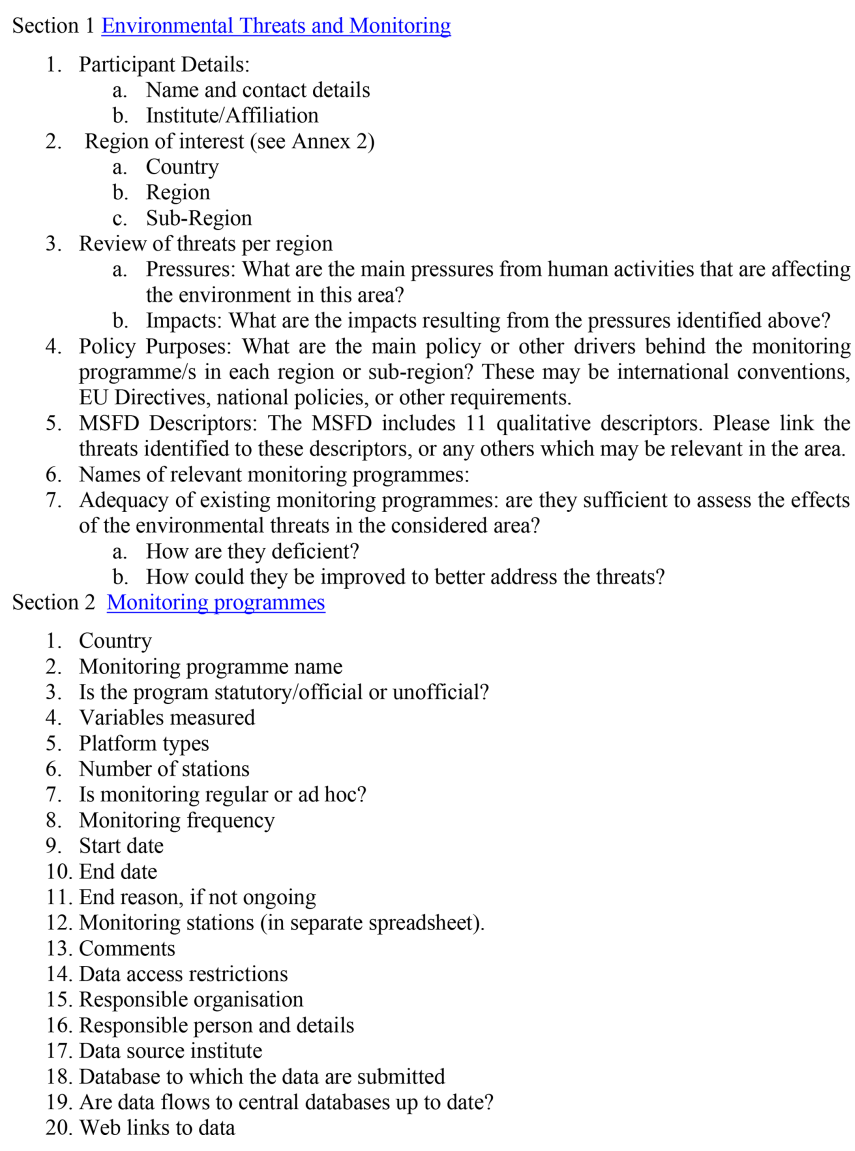

Figure 2. Format of online questionnaire.

all respondents. Opinions were also analysed within each country. Free-text responses from all respondents on the adequacy of monitoring programmes were extracted to summarize all opinions given, as were the suggestions for improving monitoring programmes that were not adequate or partly adequate to address environmental threats.

To visualize the most common themes emerging from the questions on why monitoring programmes were inadequate, word clouds were created using an online software tool (Wordle, 2018) which emphasizes the most common responses from individuals according to how many times they are mentioned.

\section{Results}

\subsection{Respondents}

The online questionnaire was completed by representatives from 12 European countries (Finland, France, Germany, Greece, Ireland, Italy, Malta, Norway, Poland, Spain, Sweden, UK; Fig. 1) representing different regional seas (Fig. 3) and their subregions (see Sects. S2 and S3). From some countries, responses were received from more than one respondent, resulting in a total of 36 responses from the 12 coun- tries. The most responses (14) were received from the UK and covered territorial waters (12 nm) as well as their Exclusive Economic Zone (EEZ) waters. Five responses were received from Greece, six from France, two from Spain, and two from Malta. Many respondents were JERICO-NEXT partners, but some were also from the wider European monitoring network. Two responses were received from people in organizations which represent multiple countries (see S3, Table S3.1). From EuroGOOS, a Swedish representative answered from a Swedish perspective. From OSPAR, a UKbased person answered for the region as a whole.

To reduce bias in the results due to different numbers of respondents from each country, views on threats, impacts, and adequacies of monitoring programmes were aggregated to give one response per country. This was considered to represent a national response (see Sect. 2.2). Data analysis showed weak relationships between the number of pressures or impacts identified per country and the number of responses per country (data not shown).

\subsection{Views on environmental threats and impacts}

\subsubsection{Pressures from human activities}

Marine litter was identified as a pressure in all of the national responses (Fig. 4). The next most commonly identified pressures were shipping (92\%), contaminants (92\%) organic enrichment $(83 \%)$, and fishing (75\%, Fig. 4). These were followed by regime change (67\%), inorganic nutrient enrichment and aquaculture (both $58 \%$, Fig. 4), dumping and aggregate extraction $(50 \%)$, and atmospheric inputs, dredging of biota, and construction or obstruction (all $42 \%$ ). Activities such as mining, water abstraction, the oil and gas industry, and coastal squeeze scored considerably lower, at $10 \%-$ $23 \%$ of responses. Only one extra pressure was added to the list provided, unexploded ordnance (UXO).

Respondents noted that the pressures affecting coastal and offshore areas were not the same. Climate-change-related pressures (regime change and ocean acidification) were considered to have large potential for widespread harm, and in all sea regions at least one respondent marked regime change as an important pressure. Thermally-driven regime change was selected in a greater proportion of responses than salinitydriven regime change.

\subsubsection{Impacts of the pressures identified}

The majority of national responses $(>70 \%)$ identified habitat loss or destruction, underwater noise, and contamination as the main impacts of human activities on the marine environment (Fig. 5). Approximately $60 \%$ of national responses identified undesirable disturbance (e.g. oxygen depletion), sediment or substrate composition, changes in community composition, harmful microorganisms, and invasive species as impacts. Half (50\%) identified changes in primary 


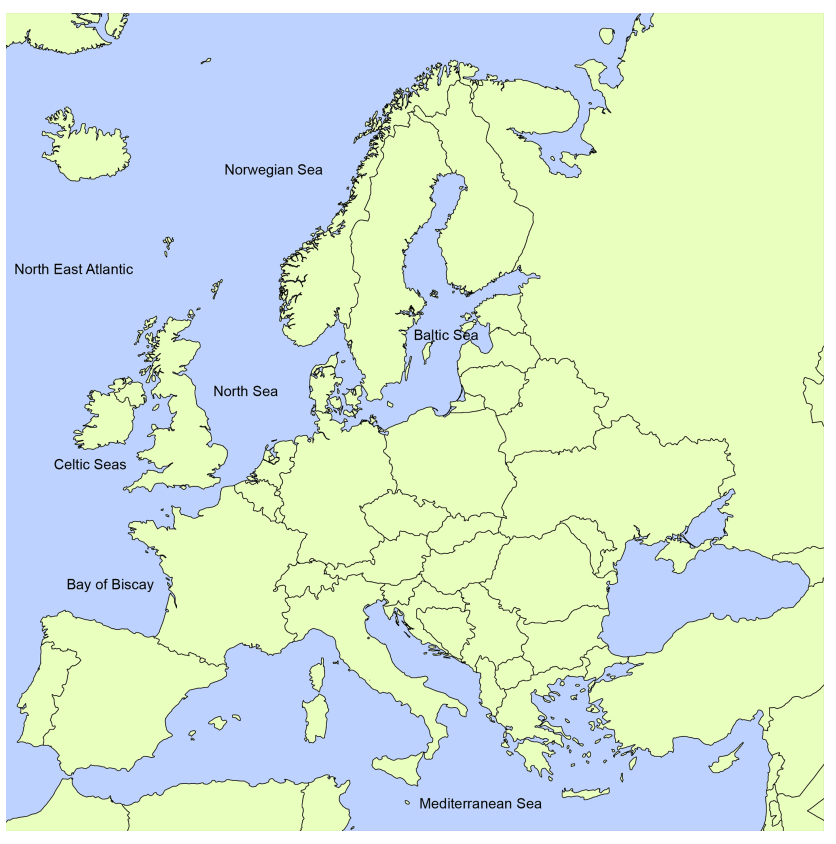

Figure 3. The regional seas represented by respondents to the questionnaire. See the Supplement for maps of regions (S2) and subregions of European seas (S3).

production, changes in species range, population change or depletion of standing stocks, biofouling, physical damage, changes in suspended sediments or turbidity, and mortality of marine life.

\subsection{Views on the main drivers of marine monitoring}

\subsubsection{Policy purposes}

The majority of national responses $(83 \%)$ identified the main drivers of the monitoring of coastal and offshore waters as the Water Framework Directive (WFD, EU, 2000) and the Marine Strategy Framework Directive (MSFD, EU, 2008, Fig. 6). Other EU directives were identified but the proportion of national responses identifying these as policy purposes for monitoring was relatively low. A total of $25 \%$ of national responses included the Urban Waste Water Treatment Directive (EC, 1991a) and Habitats and Birds Directive (Fig. 6), and $17 \%$ included the Bathing Waters Directive and the Nitrates Directive (EC, 1991b). Regional Seas Conventions were also identified as drivers of marine monitoring, with OSPAR identified by $67 \%$ of national responses and HELCOM identified by $17 \%$ of national responses. Local policy drivers were identified by $58 \%$ of national responses, but no details were given.

Respondents were asked to link environmental threats in European waters to the descriptors (D) in the MSFD (Fig. 7; see EU, 2008). Responses indicated that most threats (92\%) affect the biodiversity descriptor (D1, Fig. 7). The next most frequent responses (83\%, Fig. 7) were linked to descriptors for contaminants (D8), eutrophication (D5), and marine litter (D10); $75 \%$ of threats could be linked to the energy descriptor (D11), $67 \%$ to sea-floor integrity (D6), hydrographic conditions (D7), and non-native species (D2), and $50 \%$ to food webs (D4).

\subsubsection{Meeting requirements of policy drivers}

Much of the monitoring towards older directives is now included in WFD monitoring programmes implemented under the river basin management plans of member states. These results highlight the fact that policy drivers may change over time but the overall purposes may remain the same or similar. Regional Seas Conventions were also identified as key policy drivers of monitoring programmes, with a greater proportion of responses for OSPAR than for HELCOM.

\subsection{Monitoring programmes in each country}

In total, 36 responses on the monitoring section of the questionnaire were received from the 12 countries who participated in the online poll; 38 monitoring programmes were reported. More than half of these programmes were official or statutory programmes, and a significant proportion (28\%) were project based rather than statutory. These included the Balearic Islands multi-platform observing system (SOCIB), the UK BeachWatch litter project, and projects in Ireland (Smartbay observatory).

This is not a complete inventory of monitoring in Europe, but the responses provide examples of a variety of monitoring programmes. Entries for the UK, Ireland, and Greece appeared to be relatively comprehensive.

\subsubsection{Monitoring: variables, platforms, and frequency}

Most monitoring programmes were reported to measure temperature and salinity. A large proportion of responses (39\%$45 \%$, Fig. 8) reported measurements of nutrients, chlorophyll, and dissolved gases, although not all parameters are measured at all stations in a monitoring programme. Many variables, such as mammals, birds, biotoxins, and marine litter, are only measured in specific monitoring programmes designed for the purpose. Some variables are monitored in only a few monitoring programmes, e.g. sea level and contaminants, but this may reflect the selection of responses received. Responses to the questionnaire indicated that marine monitoring programmes provide less coverage of biological parameters (e.g. plankton $32 \%$, fish $18 \%$, benthos $18 \%$, macroalgae $11 \%$, birds $3 \%$ ) than physical water column parameters (e.g. temperature, salinity, $58 \%-61 \%$ ) and chemical parameters (e.g. nutrients, dissolved gases, $45 \%$ and $39 \%)$.

Most monitoring programmes were reported to use a vessel as a monitoring platform (Fig. 9), usually a research vessel or, for inshore monitoring, a small boat. Shore-based monitoring was also common (39\%). The use of fixed plat- 


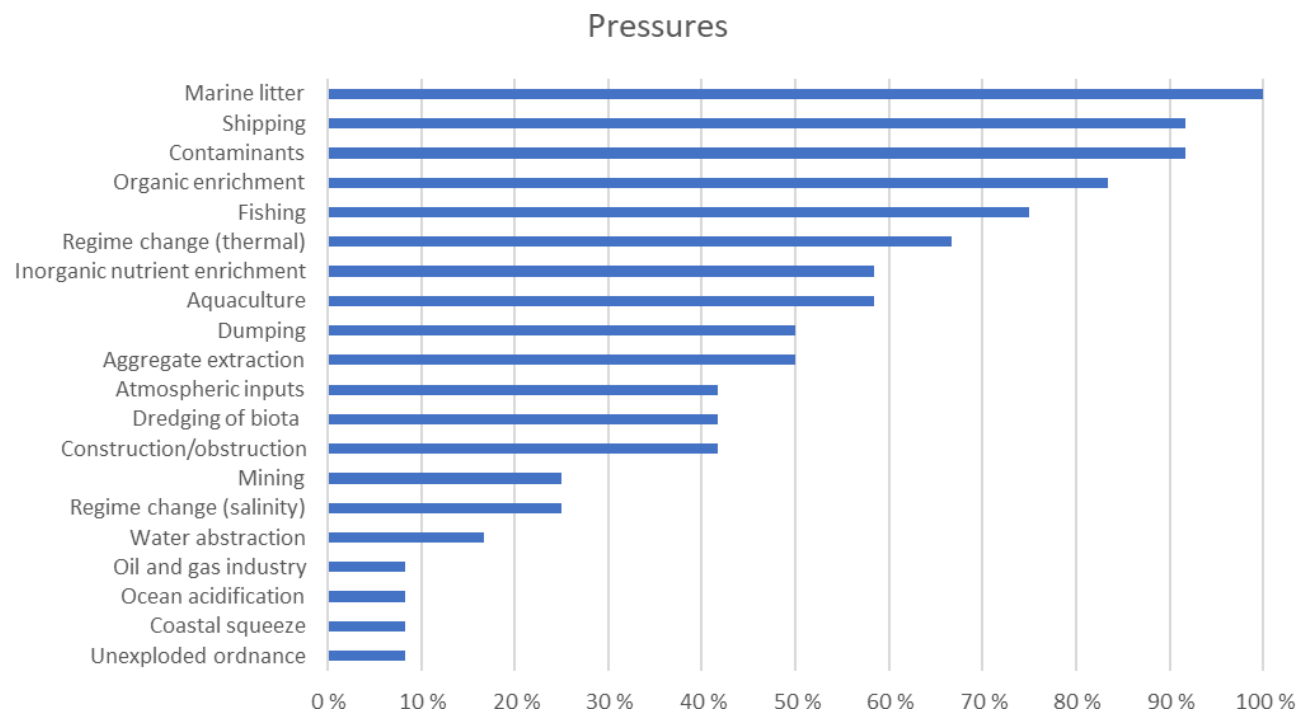

Figure 4. Frequency of national responses on pressures affecting the marine environment.

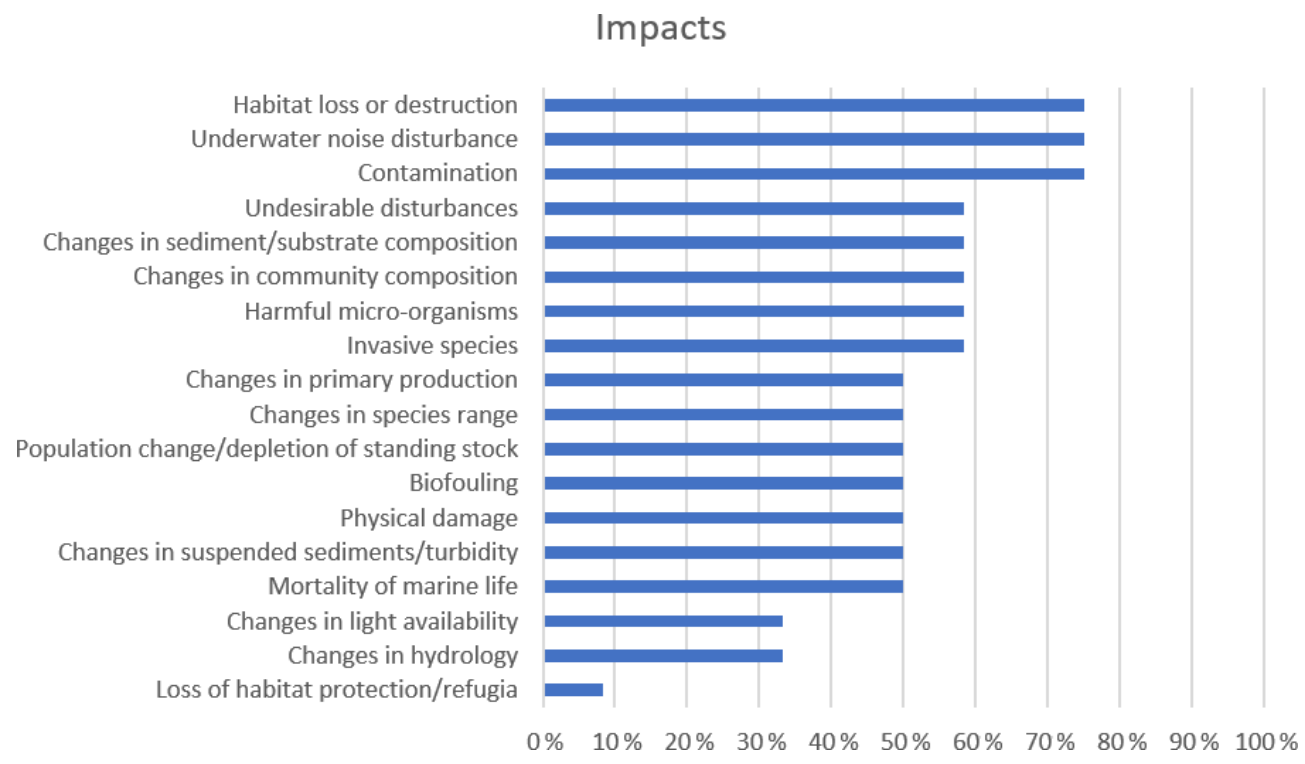

Figure 5. Frequency of national responses on impacts affecting the marine environment.

forms was indicated by $34 \%$ of respondents, including those from Belgium, Greece, Ireland, Italy, Spain, and the UK. The use of remote sensing as a monitoring platform was reported by $21 \%$ of respondents (Fig. 9). Other innovative and emerging technologies, such as autonomous vehicles, FerryBoxes, and "other" (e.g. profiling floats), were included in $\leq 11 \%$ of the responses (Fig. 9).

Responses to the questionnaire indicated that monitoring frequency (Fig. 10) is variable. The highest proportion of responses $(34 \%)$ was for continuous monitoring (e.g. from fixed platforms, moorings, or gliders). Several monitoring programmes were reported to have only annual monitoring, but to be comprehensive in terms of parameters and spatial coverage. Monitoring programmes incorporating fixed platforms or gliders were more restricted in terms of spatial coverage.

\subsubsection{Sustainability of monitoring programmes}

Responses to the questionnaire showed that $68 \%$ of the monitoring programmes have been running for longer than 10 years. The longest programme reported was the continuous plankton recorder survey by the Sir Alister Hardy Foundation for Ocean Science (SAHFOS), which has been running since 1931. Several French and Scottish monitoring programmes were reported to have been running for approximately 30 years. One respondent included a monitoring pro- 


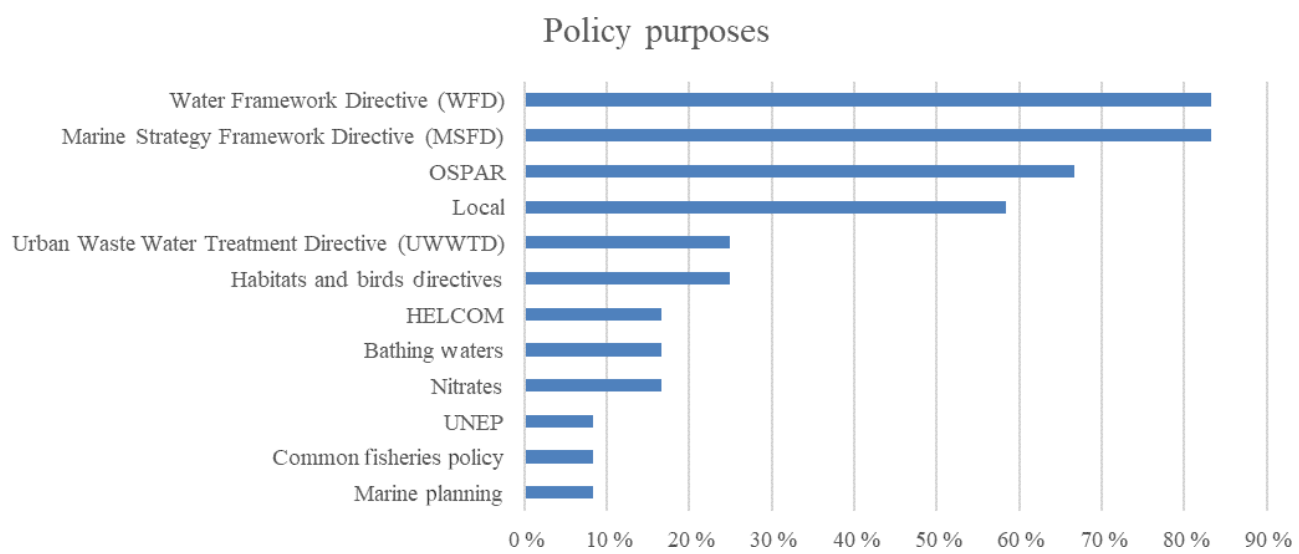

Figure 6. Main policy or other drivers for marine monitoring.

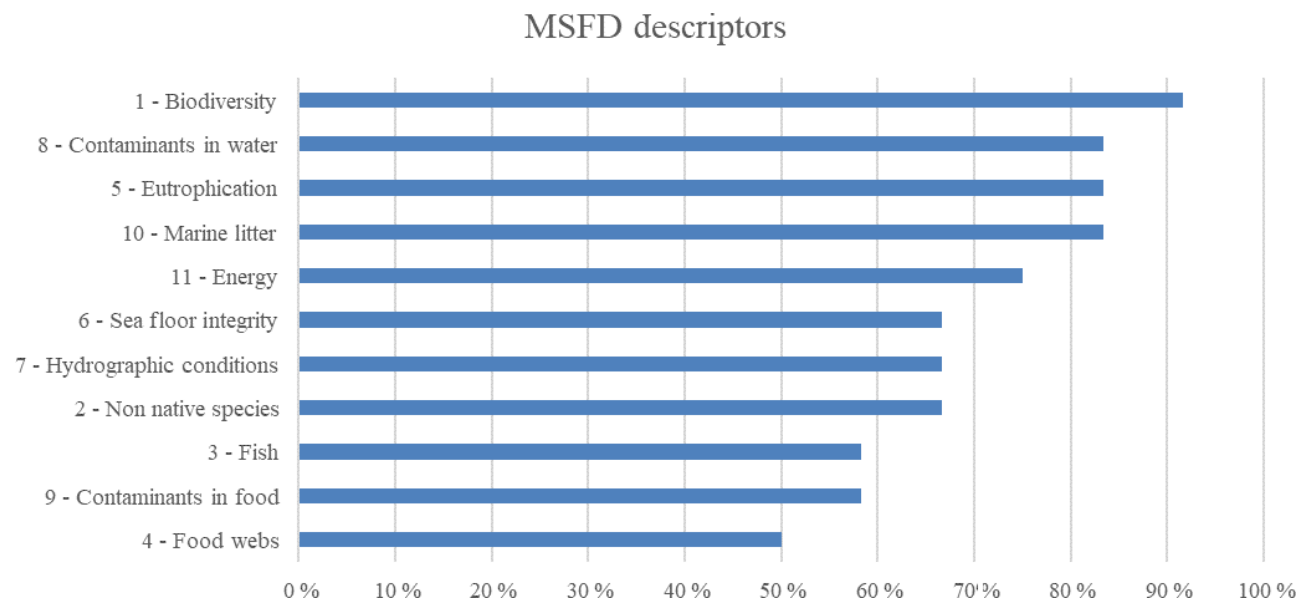

Figure 7. MSFD descriptors linked to environmental threats. The left axis shows the descriptor number and name.

gramme which ended due to lack of funding; it is likely there were many more such cases which were not reported.

\subsubsection{Data access}

The majority of respondents $(71 \%)$ reported that their monitoring programmes had no restrictions on data access. Where data access is restricted, most programmes make the data available on request, subject to information on the intended purpose or use of the data, signing of a licence agreement, and/or requirements to acknowledge the source of the data (e.g. through the use of data DOIs - digital object identifiers).

Respondents reported that data were submitted most commonly to local and/or national databases but frequently also to ICES databases, EMODnet, or Copernicus. For the majority of programmes, data flows to these central databases were considered not up to date, indicating that not all monitoring data are centrally available or that there is a time lag in the submission of data.

\subsection{Gaps identified in current monitoring programmes}

In terms of providing the information required to monitor environmental threats, $12 \%$ of all the respondents to the questionnaire considered monitoring programmes to be adequate, while $28 \%$ indicated that monitoring programmes were not adequate, and $60 \%$ considered monitoring programmes to be partially adequate (Fig. 11).

When there was more than one respondent per country, responses were varied (Fig. 12), with the majority of responses indicating inadequate monitoring. In the UK, for example, from which 14 responses were received, most responses $(57 \%)$ indicated that monitoring was partly adequate and $29 \%$ that monitoring was not adequate. Two respondents $(15 \%)$ felt that monitoring programmes were adequate. In France, from which six responses were received, the majority $(83 \%)$ considered monitoring not adequate, and the remaining one felt it was adequate. In Greece, four out of five respondents $(80 \%)$ felt monitoring was not adequate, and one considered it to be partly adequate. In countries with two responses (Italy, Malta, and Spain), one indicated that monitor- 


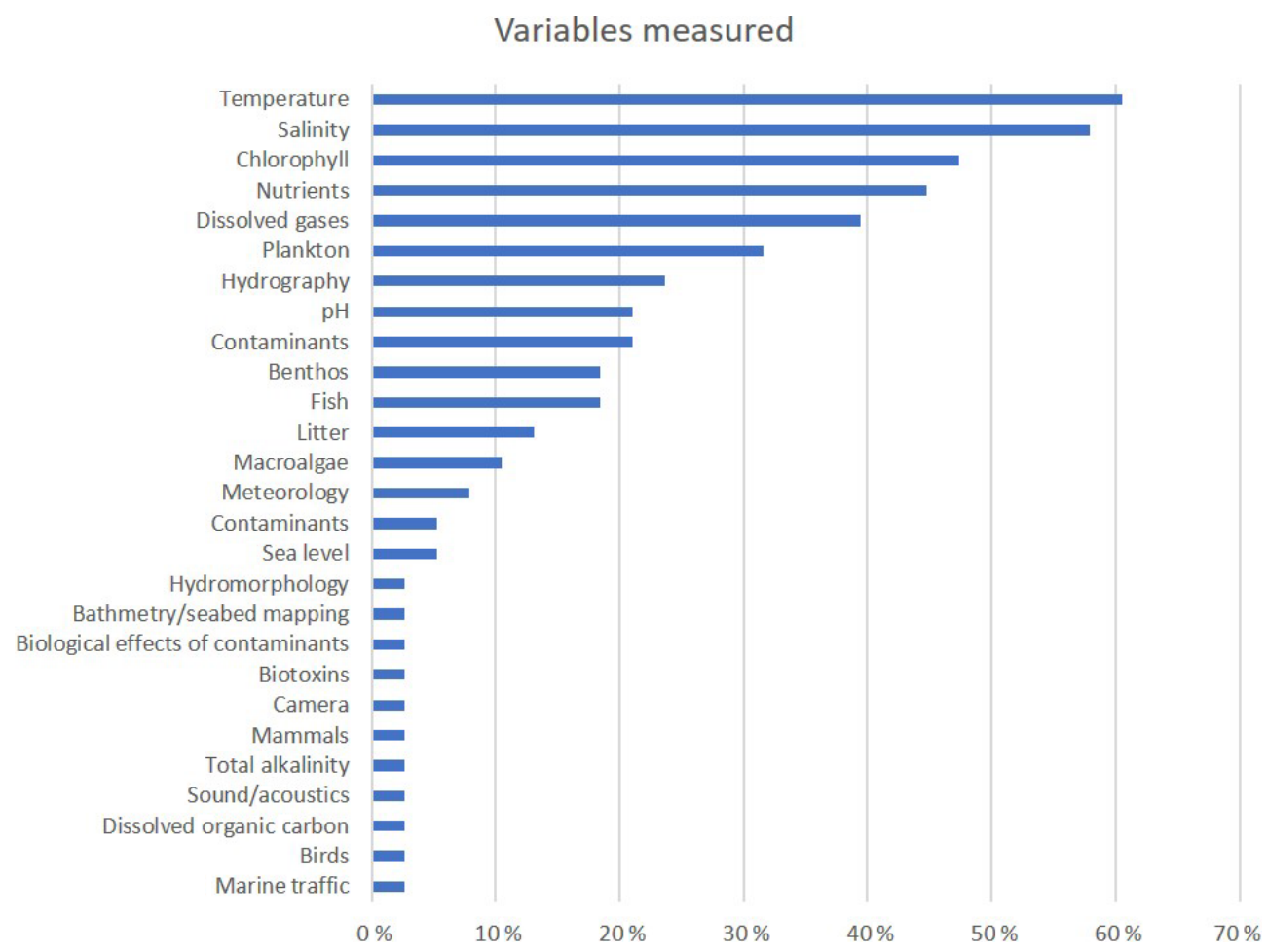

Figure 8. Variables measured in marine monitoring programmes.

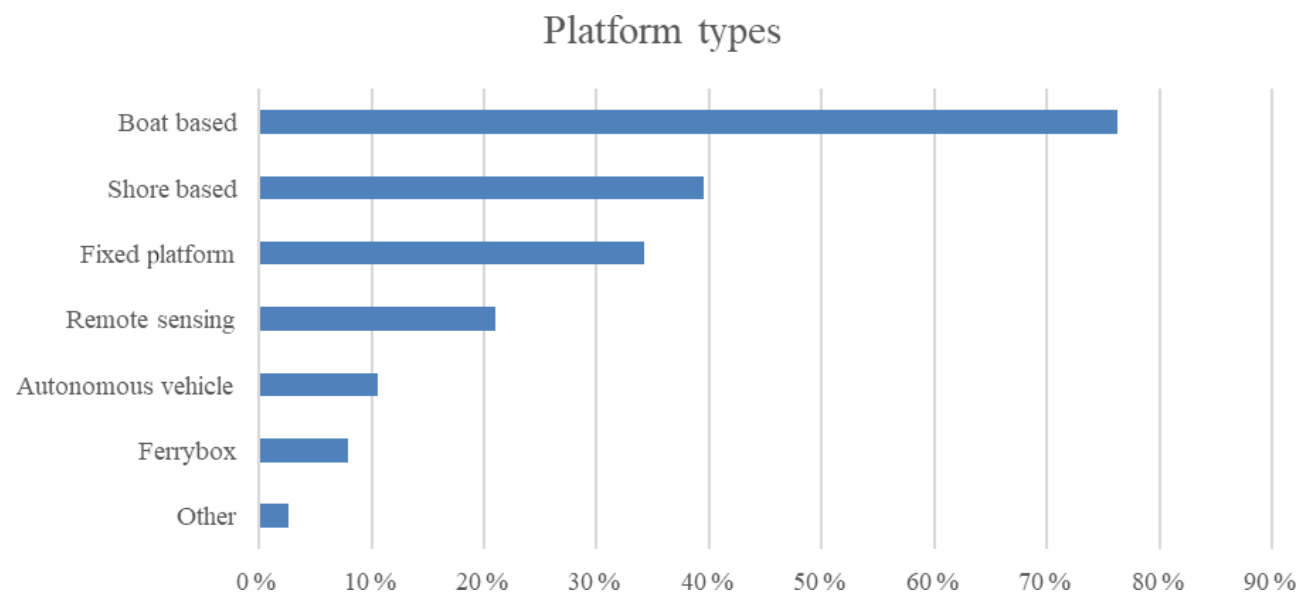

Figure 9. Platform types used in marine monitoring.

ing was not adequate, while one felt it was partly adequate. In countries with one respondent, responses mostly indicated that monitoring was partly adequate (Finland, Ireland, Norway, Sweden). In Poland, the national representative reported that monitoring was adequate.

\section{Where monitoring is not adequate}

Responses were focussed around a few key issues (see Fig. 13) which appeared to be related mostly to insufficient resolution in time and space, insufficient data or parameters measured, and lack of integration (e.g. of monitoring programmes, indicators, and descriptors).

A number of respondents stated that there is insufficient monitoring for some of the MSFD descriptors. These descriptors included biodiversity, food webs, marine litter (including microplastics), underwater noise, emerging contaminants, and emerging pollutants. However, no details were given. It was noted that coupling between physics and biology in response to environmental pressures is typically not included in monitoring programmes focussed on individual descriptors. One respondent indicated that methodologies 


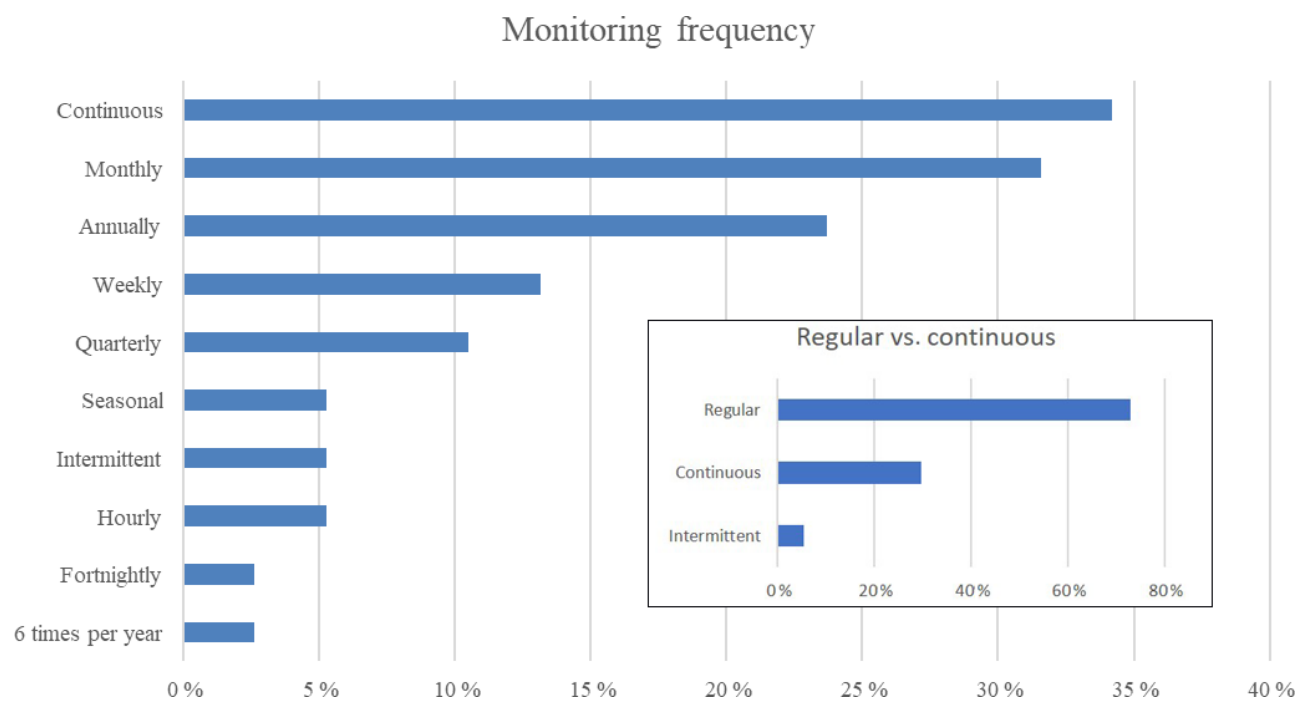

Figure 10. Frequency of monitoring. The main graph shows results for all options given in the questionnaire. The inset combines these into three categories: continuous and intermittent are the same as in the main graph, and "regular" indicates that all other options are combined.

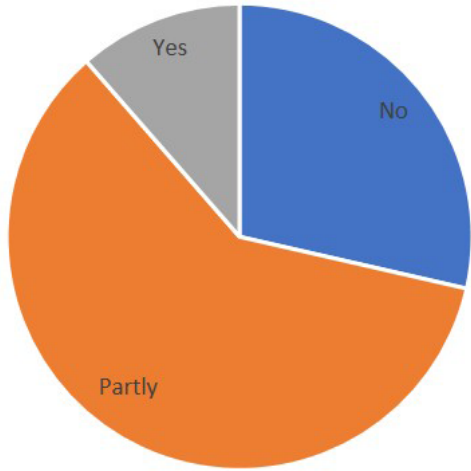

Figure 11. Proportion of all respondents who considered their monitoring programmes to be adequate (yes), inadequate (no), or partly adequate (partly).

and approaches were not state of the art; for example, the focus during benthic sampling was on taxonomy instead of ecosystem functions and services.

Two respondents highlighted concerns about the links to policy drivers, suggesting that monitoring was reactive rather than proactive. One of these respondents commented that monitoring programmes develop to respond to pressures and impacts. The other highlighted concerns related to unexploded ordnance, for which there seems to be very little political or commercial interest in finding and making safe dumped munitions until a person or marine organism is found with injuries or abnormal growth.

Examples of monitoring programmes with low spatial resolution were given for point source monitoring of contaminant inputs, controls and improvements, benthic habitats for the wider environment and deep-sea areas, and subregions of the Mediterranean Sea. Examples of inadequate monitoring of parameters were given for the Mediterranean Sea, including zooplankton, phytoplankton compositions, marine mammals, reptiles, birds, invasive species, marine litter, and contaminants in sediment and biota.

\section{Improving monitoring programmes}

The respondents highlighted key gaps between the environmental pressures or threats and the monitoring of their impacts. Suggestions were given for improving monitoring programmes considered not adequate or partly adequate. These were focussed on the improved design of monitoring programmes, as well as increased effort, observation, and research, including the following:

- improved spatial and/or temporal resolution and assessment of emerging threats;

- improved monitoring of biological parameters and coupling between biological and physical or chemical parameters, particularly those which provide information on ecosystem function (examples were given for poorly covered habitats, microbes, zooplankton, marine mammals, and biodiversity components not yet monitored);

- increased use of new technologies (e.g. remote sensing, FerryBoxes, gliders) and methodologies (e.g. molecular techniques);

- maintaining and/or developing a limited number of long-term (fixed-point) monitoring sites to monitor changes in baseline conditions (chemistry, ecotoxicology, and ecosystem structure) in response to climate change or acidification and diffuse inputs; 
Are monitoring programs adequate to address threats?

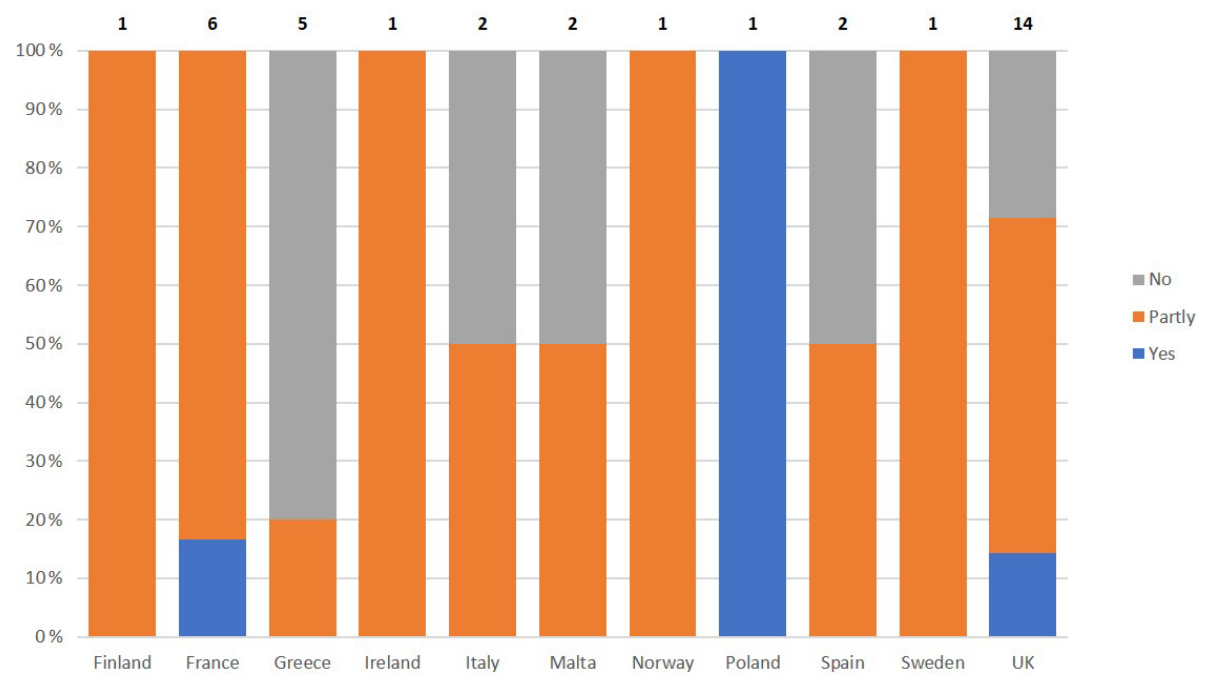

Figure 12. Responses by country showing the proportion of respondents who considered their monitoring programmes to be adequate (yes), inadequate (no), or partly adequate (partly). The number of respondents per country ranged from 1 to 14 (see numbers in bold).

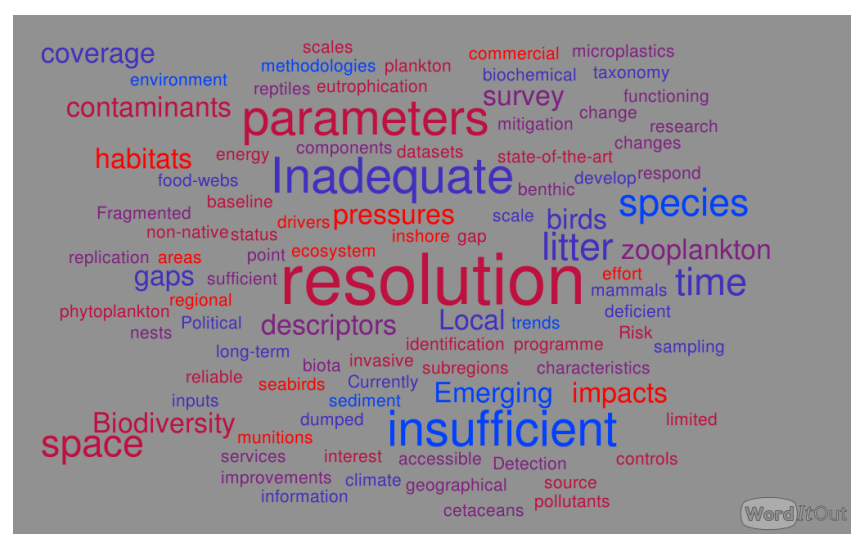

Figure 13. Keywords used in views on partially adequate or inadequate monitoring programmes. Font sizes indicate the most common responses from individuals according to how many times they are mentioned.

- making better use of low-cost biochemical sensors on low-cost platforms;

- improved data flows (submission of data to centralized and/or open-access databases);

- more integrated cross-disciplinary approaches, e.g. through more coordinated monitoring across descriptors;

- improved monitoring design to create programmes which are fit for multiple purposes, e.g. to take into account regional or national specificities or requirements (e.g. subregions of regional seas; rigid baseline ecological assessment at local scales; increased monitoring in high-risk areas), incorporate newer threats (e.g. phosphorous-based flame retardants, microplastics, noise), and be more proactive regarding threats likely to cause harm to or changes in biota, e.g. unexploded ordnance (UXO);

- including flexible research and/or investigative monitoring to increase knowledge of specific impacts; and

- securing funding for long-term monitoring programmes.

\section{Discussion}

\subsection{Polling approach}

The opinion poll carried out during this study had a limited number of participants, as it was targeted towards scientists and managers with the relevant expertise and experience in European countries adjoining regional and/or subregional seas. In order to minimize bias which might be introduced by some countries providing more individual responses than other countries, project partners were expected to develop national responses and were given approximately 5 months to do so. When there was more than one response from a country, results on views or opinions were combined to represent a national view.

Responses on monitoring programmes were not combined, as these were considered to provide useful detail on gaps in monitoring, and no monitoring programmes had duplicate responses. 
Despite a number of limitations in the polling approach, responses provided valuable insights on the environmental pressures and their impacts, as well as on gaps in monitoring the impacts. A recent study in estuaries and coastal waters in the North Sea-Baltic Sea transition zone (Andersen et al., 2019) using 35 databases yielded results which are broadly similar (see below).

\subsection{Drivers of marine monitoring}

Most national responses were focussed on policy drivers such as EU directives and regional conventions based on the ecosystem approach. These responses are likely to have been influenced by the overall context of the JERICO-NEXT project and its emphasis on biogeochemical processes and the coupling between physics and biology. Responses may also have been influenced by the drop-down list of options from which to select answers, although the option was given to add responses.

Interestingly, local drivers scored quite highly. No details or examples were given by any of the respondents but may include monitoring towards impact assessments for a variety of reasons, such as the development of local fisheries or recreational activities, or to meet conservation objectives (e.g. for marine protected areas). However, such monitoring would be included under policy drivers such as the Habitats and Birds Directives or marine planning, and relatively few responses $(\leq 25 \%)$ indicated these as drivers for marine monitoring. It is possible that local drivers included research projects or programmes, but this seems unlikely as the poll was focussed on monitoring rather than research. This highlights a potential weakness of the aims of this study and indeed the JERICO-NEXT project, as it did not include an objective to identify gaps in understanding and how to provide better linkages between research and monitoring. Certainly, ongoing national monitoring programmes are focussed on reporting to directives and international obligations, and not to contribute to a better understanding of the possible impacts of the threats.

Complex linkages between pressures and impacts and the cumulative effects of multiple pressures are not currently well addressed by any of the reported monitoring programmes. The MSFD was intended as a holistic approach to assessments, but descriptors are currently assessed separately. Developments are underway to move assessments towards a more integrated cross-disciplinary ecosystem approach both in Europe (e.g. OSPAR ${ }^{12}$; EEA, 2011, 2015b; HELCOM, 2018) and globally (Schmidt et al., 2019). This

\footnotetext{
${ }^{12} \mathrm{See} \quad$ https://oap.ospar.org/en/ospar-assessments/ intermediate-assessment-2017/introduction/

assessment-process-and-methods/ (last access:

2 December 2019) and https://oap.ospar.org/en/ ospar-assessments/intermediate-assessment-2017/

chapter-6-ecosystem-assessment-outlook-developing-approach-cumul/ (last access: 2 December 2019).
}

will require more coordinated monitoring across descriptors and a focus on acquiring long-term datasets, particularly for addressing cross-cutting issues such as climate change and ocean acidification (Tett et al., 2013; Schmidt et al., 2019). Responses indicating that a number of monitoring programmes have been running for more than 10 years are extremely positive, providing data to allow for the detection of temporal trends in pressures and their impacts on the marine environment. Evidence that a significant proportion of monitoring is largely project based rather than statutory indicates some degree of risk to the sustainability of monitoring. EuroGOOS conducted a survey of sea level monitoring and found similar issues; less than half of the organizations responding indicated that there were no funding issues for tide gauges, and many had reduced funding or uncertain future funding (EuroGOOS, 2017). Similar issues are encountered in other parts of the world where monitoring is supported by both academic and private research and hampered by a lack of sustained funding from governments from which grants are often short term (Weller et al., 2019).

With the majority of responses to the online poll indicating that the main policy drivers of current monitoring are the MSFD and WFD, rather than earlier directives such as the Urban Waste Water Treatment Directive (UWWTD), the Nitrates Directive, and the Habitats Directive, it is clear that policy drivers and requirements for meeting policy needs change over time. This suggests that monitoring programmes should be underpinned by high-level scientific objectives and that research and monitoring should be well integrated. Data sharing, such as through the JERICO-NEXT research infrastructure, coastal observatories, and the EMODNet data infrastructure (Miguez et al., 2019), is vital to the current and future integration of research and monitoring (Farcy et al., 2019). Furthermore, the availability of data at local and regional scales is essential for the development of future monitoring and assessment approaches, particularly as new technologies and assessment tools are developed and become more readily available (e.g. Borja et al., 2019; García-García et al., 2019).

\subsection{Views on environmental threats and impacts}

Respondents were provided with comprehensive lists of key environmental threats and impacts informed by previous studies, with an option to add to the list. One item, UXO, was added to the list of pressures by one country. This pressure was considered to be outside the scope of the JERICO-NEXT project but may be useful in other contexts. No new items were added to the list of impacts in the national responses.

The most commonly identified pressures or threats to the marine environment due to manageable human activities were considered to be marine litter, shipping, contaminants, organic enrichment, fishing, and regime change.

The main impacts of threats to the marine environment (i.e. $>70 \%$ of national responses) were identified to be habi- 
tat loss or destruction, underwater noise, and contamination. A total of $60 \%$ of national responses identified impacts to be undesirable disturbance (e.g. oxygen depletion), changes in sediment or substrate composition, changes in community composition, harmful microorganisms, and invasive species.

In a recent study, Andersen et al. (2019) analysed 35 publicly available datasets from Danish marine waters and obtained broadly similar results. These authors found the main stressors (pressures) across a range of water types to be nutrients, climate anomalies, non-indigenous species, noise, and contaminants. Some stressors (e.g. fisheries, contaminants, noise) were shown to have a relatively higher impact in open waters, while some stressors (e.g. nutrients, shipping, physical modification) had a relatively higher impact within fjord or estuarine systems. Some of these stressors (pressures) were considered to be impacts in this study, e.g. nonindigenous (invasive) species. It was recognized that it can be difficult at times to distinguish between pressures and impacts. For example, shipping is a pressure and one of its impacts can be the introduction of invasive species via ballast water, but these invasive species can themselves become a pressure on the native ecosystem.

\subsection{Monitoring programmes}

Most respondents were of the view that current monitoring is partially adequate or not adequate. The range of views given between and within countries suggest that a broad spectrum of participants responded to the questionnaire (Fig. 12). These views likely reflect the different experiences of respondents in their areas of expertise and in their countries.

Key issues identified in responses (i.e. insufficient resolution in time and space, insufficient data or parameters measured, and lack of integration) indicate gaps in monitoring. Suggestions for improved monitoring programmes were targeted at these gaps and need to be considered in detail to feed into science and monitoring strategies. These issues are discussed in Sect. 5.5.

Few respondents completed the second questionnaire on monitoring programmes, so a subset of European monitoring programmes was reported. The opinions may therefore reflect the views of the JERICO community, particularly on the measurement of limited parameters (with a focus on physical and biogeochemical parameters, e.g. temperature, salinity, and chlorophyll). These views are supported by information available via a number of projects and infrastructures (e.g. JERICO, DEVOTES, COPERNICUS, EMODnet, EMSO ERIC, and AtlantOS; links given in Sect. 1), all of which indicate the need to improve the availability of datasets, especially biological components (e.g. fish, seabirds, and mammals). Furthermore, limited monitoring of pressures indicates some mismatch between the pressures and impacts considered by respondents to be important and those actually monitored.
Several programmes were reported to be making use of alternative platforms such as remote sensing, autonomous vehicles, and FerryBoxes. These technologies are likely to complement other monitoring platforms (e.g. boat based) rather than replace them altogether. Remote sensing data, for example, are limited to surface monitoring of particular parameters and still require in situ data for calibration and validation (Groom et al., 2019). FerryBox monitoring can improve coverage in space and time (e.g. Grayek et al., 2011) but is similarly limited in terms of depth and parameters (Petersen, 2014).

Suggestions given for improving monitoring programmes are supported by many studies on the development of existing and new technologies. Davidson et al. (2019) provide an overview of the need for operational oceanographic systems, which include a multi-platform observation network, as well as systems for data management, data assimilation and prediction, and data dissemination and accessibility. Key components of such systems include an integrated approach (She et al., 2019), partnerships and shared approaches for monitoring, assessment and data (Bax et al., 2019; Canonico et al., 2019; Míguez et al., 2019; Schmidt et al., 2019; Stammer et al., 2019; Tanhua et al., 2019; Weller et al., 2019), instrumented moorings (fixed platforms; Bailey et al., 2019), and new methodologies for monitoring, including in situ biochemical, biological, and molecular sensors (reviewed by Wang et al., 2019).

\subsection{Resolution in time and space}

The scale of impacts varies widely, with some activities, such as the construction of a wind farm, having a potentially high impact on a small area, whereas activities such as fishing are more widespread. The impact of human activities also depends on the vulnerability of the habitat in question. For example, in the southern Celtic Sea, fragile benthic habitats with cold-water corals are highly impacted by sea-floor activities. Some impacts, such as noise disturbance, depend on the intensity of the activity and will be concentrated in areas with high shipping activity or during periods of construction.

Countries such as the UK adopt a risk-based monitoring approach, which was considered to result in fragmented monitoring. Examples of low spatial resolution were given for the Continuous Plankton Recorder (CPR) survey, one of the key plankton datasets, for which spatial gaps exist throughout EU waters. Spatial resolution was also considered to be low for some habitats, as not all habitats are covered by monitoring programmes, and for monitoring of marine litter and non-native species.

In terms of spatial resolution, other responses indicated that not all parameters are monitored adequately. Even for parameters that were reported as monitored in many monitoring programmes, e.g. chlorophyll (47\% of reported programmes), monitoring may not be adequate in space or time 
(see Baretta-Bekker et al., 2015, Annex $1^{13}$ ). A more detailed analysis looking at the distribution of the monitoring of different parameters in space would be required to assess this. The WFD does not require zooplankton monitoring, but some indicators under the MSFD do require information on zooplankton. Although phytoplankton is monitored inshore, the data are disparate and mainly used to report on potential health issues due to toxin-producing algae.

For temporal resolution, examples were given for a number of threats where the monitoring period was considered to be inadequate. For example, for statutory monitoring of impacts such as those from dredging and disposal, monitoring is often over timescales which are too short (2-5 years) to properly assess the impacts on the biological communities. This also applies to seabird and cetacean monitoring, which is out of the scope of JERICO-NEXT. Some monitoring programmes may be inadequate in terms of temporal frequency: $24 \%$ of monitoring programmes reported had annual monitoring, which may fail to detect impacts throughout the year. Monitoring frequency is likely to be strongly influenced by platform types, with increasing use of fixed platforms, moorings, or gliders giving a high proportion (34\%, Fig. 10) of responses for continuous monitoring. Certainly, platforms such as moorings can provide high-frequency temporal resolution (e.g. Mills et al., 2005; Greenwood et al., 2010) for the parameters they measure, predominantly physical and chemical parameters (such as temperature, salinity, light, dissolved oxygen) with biological parameters limited to phytoplankton fluorescence or chlorophyll. Monitoring more complex biological parameters (such as community species composition in the benthic and/or pelagic compartments) at high frequency appears particularly challenging because of the limited degree of development of appropriate semi-automatic tools. To date, routinely using such techniques at a high frequency of acquisition would still require a massive level of skilled manpower, although new developments of molecular tools would clearly help to tackle the challenge in the future. Additionally, even where low-cost sensors for biological parameters exist, analysing the large volumes of data produced remains a large challenge.

Addressing the issue of scales is essential in establishing a future pan-European monitoring programme, particularly for biological parameters. Monitoring these parameters is more limited than for physical parameters. The reasons for this include the following.

1. The types of biological data that can be automatically or semi-automatically acquired is low despite recent technological developments (including those achieved within FP7-JERICO and JERICO-NEXT), which limits

\footnotetext{
${ }^{13}$ See also https://oap.ospar.org/en/ospar-assessments/ intermediate-assessment-2017/pressures-human-activities/ eutrophication/chlorophyll-concentrations/ (last access: 2 December 2019).
}

the spatio-temporal coverage of biological or biogeochemical datasets.

2. Miniaturization of sensors allowing for implementation on platforms such as autonomous underwater vehicles (AUVs) and floaters is more feasible for physical and chemical parameters, which results in better spatial and synoptic coverage.

3. Scaling up from "point" observations to wider areas most often relies on modelling. Physical models are more advanced than biogeochemical and biological models, which also increases the importance of scales of biological observations.

\subsubsection{Small-scale threats and disturbances}

The majority of threats impact at relatively small spatial and temporal scales, at least initially. Examples include the accumulation of marine litter, the development of harmful algal blooms, and invasion by non-native species, which occur locally in the first instance, as influenced by point sources and the characteristics of the abiotic and biotic components of the environment. In these examples, there is no initial discrepancy in spatial scales between monitoring and threats and disturbances. However, the number of monitored habitats clearly remains too low, as indicated by responses to the questionnaire.

Monitoring effort should be sufficient in time and space to (1) detect the effects of new threats and disturbances acting in different locations within the same habitat, (2) assess the consequences of an identified threat or disturbance at larger scales, and (3) assess the cumulative effects of multiple threats.

\subsubsection{Large-scale threats and disturbances}

Some environmental threats act over large spatial scales, such as thermal regime change or ocean acidification. There is a discrepancy between the (large) spatial extent of the threat or disturbance and the (small) scale at which the monitoring is performed (station). This may be addressed to some extent by (1) the use of mobile monitoring techniques such as FerryBoxes, which allow for large geographical coverage albeit on a limited timescale, and (2) the fact that only a small number of fixed monitored sites is required to monitor this kind of threat disturbance. Factors to consider include the following.

i. Different biological communities may not be affected in the same way by the same level of a given (widespread) environmental pressure. Grémare et al. (1998) and Labrune et al. (2007), for example, clearly showed that in the Gulf of Lion, the composition of the two shallowest communities (i.e. littoral fine sands and littoral sandy muds) is most affected by climatic oscillations. A sound assessment of large-scale threats and/or disturbances at the reporting scales should therefore not rely 
on the sampling of a single habitat or even a limited number of habitats. Conversely, the monitoring strategy of large-scale threats or disturbances should ideally encompass all the habitats present in the reporting area.

ii. The representativeness of monitoring data is often limited. For example, highly mobile fauna (e.g. marine mammals or birds) are often used as proxies for largescale threats or disturbances because they can be found over large spatial scales and because, as for predators, their ecophysiology and/or population dynamics tolerate a large set of ecological processes. The probability of these organisms being sampled with confidence is directly proportional to the sampling effort and to their relative accessibility. Current monitoring resources deployed in the UK, for example, do not have the power to detect trends in all seabird and cetacean species or identify the drivers of their population change. A similar example was given for Malta, where only the most accessible marine bird nests are currently monitored as part of the seabird monitoring programme.

\subsubsection{The real world: a mixture of threats and disturbances at small and larger scales}

At the scale of global coastal marine ecosystems, several environmental pressures act simultaneously, each having its own spatial resolution and temporal dynamics. Halpern et al. (2008) and Crain et al. (2009) found that no fewer than five pressures overlap anywhere in the world's oceans. Potential cumulative and/or interactive effects need to be addressed, for example by considering the following.

i. Monitoring should be based on the largest spatial entity within which the comparisons of community compositions are sound, e.g. habitats or ecohydrodynamic regions (van Leeuwen et al., 2015).

ii. The monitoring of each habitat or region should include a sample size large enough to allow for the detection and the variability in the effects of small- and large-scale threats or disturbances.

iii. Within a given reporting area, a monitoring programme should include the highest possible number of relevant habitats in order to facilitate the detection of a new small-scale threat and/or disturbance and the upscaling of large-scale threat and/or disturbance effects.

Such monitoring programmes would require considerable effort, highlighting the need to define and characterize relevant environmental threats in each habitat or region.

The feasibility of the different suggestions for improved monitoring needs to be considered. This includes the identification of "new technologies" and how best to incorporate them into monitoring programmes. Projects such as JERICO-NEXT work to harmonize new technologies which may be able to solve some problems of scale through highfrequency monitoring. For example, instruments such as flow cytometers and multispectral fluorometers can measure continuously on research vessels or buoys and provide good spatial and temporal coverage. However, integrating these data types into existing monitoring presents several challenges: data may be in a very different format (continuous versus discrete samples, functional groups vs. taxa), adopting new methods may affect the integrity of long time series, or there may be difficulty gaining acceptance and confidence in new methods. Similar challenges exist with using remotely sensed data instead of field measurements (e.g. for turbidity, chlorophyll), and these also still require ongoing in situ measurements for validation (De Cauwer et al., 2004).

\section{Conclusions}

This study consolidates the main conclusions from the Dobris Assessment (EEA 1995) and more recent studies (e.g. EEA, 2008a, b, 2015a; DEVOTES, 2014; Tett et al., 2013; Zampoukos et al., 2013; García-García et al., 2019), highlighting the need for improved monitoring of environmental threats in European coastal environments.

Most respondents to the JERICO-NEXT questionnaire considered the current monitoring of threats to be partially adequate or not adequate. The majority of responses were related to the spatial and/or temporal scales at which monitoring takes place and the inadequate monitoring of particular parameters. Monitoring of biological parameters was considered to be generally inadequate, with insufficient focus on coupling between biological and physical or chemical parameters

Suggestions for improved monitoring programmes included improved design, increased monitoring effort, better linkages with research, better use of new technologies (such as remote sensing, FerryBoxes, and gliders) and methods (such as molecular techniques), and improved data flows. Improved monitoring programmes should be fit for policy and management purposes, as well as underpin longer-term scientific objectives which cut across policy and other drivers. Improved designs of monitoring programmes need to consider the cumulative effects of multiple pressures. JERICORI has high potential to fill in some of the observation gaps, especially those related to physical and biogeochemical parameters, and the coupling between biology and physics across scales needed for integrated ecosystem-based understanding. The particular challenge of simultaneously observing physical, chemical, and biological parameters for assessments of complex coastal processes remains an open issue in relation to the temporal scale of sampling. This will be addressed in the JERICO science strategy under development (Grémare et al., 2017; Farcy et al., 2019).

Certainly, one of the main challenges for the European marine research community is to increase the consistency and 
the sustainability of dispersed networks and infrastructures by integrating them within a shared pan-European framework. The long history of national monitoring programmes which have been expanded, modified, and developed over time, together with methodological differences between nations, results in difficulties for the integration and holistic assessment of the data (at a regional sea level), which JERICORI may contribute to solving.

Data availability. The questionnaire responses are available on the Cefas Data Hub at: http://data.cefas.co.uk/\#/View/20302 (last access: 14 February 2020).

Supplement. The supplement related to this article is available online at: https://doi.org/10.5194/os-16-235-2020-supplement.

Author contributions. SP, KC, DD, AG, and GB designed the questionnaire. KC downloaded and analysed the results. SP and KC prepared the paper with contributions from all co-authors.

Competing interests. Six of the authors declare that they have no conflict of interest. Veronique Créach is a member of the editorial board on other topic areas in the Special Issue.

Special issue statement. This article is part of the special issue "Coastal marine infrastructure in support of monitoring, science, and policy strategies". It is not associated with a conference.

Financial support. This research has been supported by Horizon 2020 (grant no. JERICO-NEXT (654410)).

Review statement. This paper was edited by George Petihakis and reviewed by Sander Wijnhoven and one anonymous referee.

\section{References}

Andersen, J. H., Al-Hamdani, Z., Harvey, E. T., Kallenbach, E., Murray, C. and Stock, A.: Relative impacts of multiple human stressors in estuaries and coastal waters in the North Sea - Baltic Sea transition zone, Sci. Total Environ., 704, 1-15, https://doi.org/10.1016/j.scitotenv.2019.135316, 2019.

Bailey, K., Steinberg, C., Davies, C., Galibert, G., Hidas, M., McManus, M. A., Murphy, T., Newton, J., Roughan, M., and Schaeffer, A.: Coastal mooring observing networks and their data products: Recommendations for the next decade, Front. Mar. Sci., 6, 1-22, https://doi.org/10.3389/fmars.2019.00180, 2019.

Baretta-Bekker, H., Sell, A., Marco-Rius, F., Wischnewski, J., Walsham, P., Malin Mohlin, L., Wesslander, K., Ruiter, H., Gohin, F., and Enserink, L.: The chlorophyll case study in the JMP NS/CS project. Document produced as part of the EU project: "Towards joint Monitoring for the North Sea and Celtic Sea" (Ref: ENV/PP 2012/SEA), 72 pp. Annex I: Baretta-Bekker, Hanneke, Inventory of the Chlorophyll-a data in the ICES database, Ifremer, 23 pp., 2015.

Bax, N. J., Miloslavich, P., Muller-Karger, F. E., Allain, V., Appeltans, W., Batten, S. D., Benedetti-Cecchi, L., Buttigieg, P. L., Chiba, S., Costa, D. P., Duffy, J. E., Dunn, D. C., Johnson, C. R., Kudela, R. M., Obura, D., Rebelo, L. M., Shin, Y. J., Simmons, S. E., and Tyack, P. L.: A response to scientific and societal needs for marine biological observations, Front. Mar. Sci., 6, 1-22, https://doi.org/10.3389/fmars.2019.00395, 2019.

Bean, T. P., Greenwood, N., Beckett, R., Biermann, L., Bignell, J. P., Brant, J. L., Copp, G. H., Devlin, M. J., Dye, S., Feist, S. W., Fernand, L., Foden, D., Hyder, K., Jenkins, C. M., van der Kooij, J., Kröger, S., Kupschus, S., Leech, C., Leonard, K. S., Lynam, C. P., Lyons, B. P., Maes, T., Nicolaus, E. E. M., Malcolm, S. J., McIlwaine, P., Merchant, N. D., Paltriguera, L., Pearce, D. J., Pitois, S. G., Stebbing, P. D., Townhill, B., Ware, S., Williams, O., and Righton, D.: A review of the tools used for marine monitoring in the UK: combining historic and contemporary methods with modeling and socioeconomics to fulfill legislative needs and scientific ambitions, Front. Mar. Sci., 4, 1-29, https://doi.org/10.3389/fmars.2017.00263, 2017.

Borja, A., Garmendia, J. M., Menchaca, I., Uriarte, A., and Sagarmínaga, Y.: Yes, We Can! Large-Scale Integrative Assessment of European Regional Seas, using Open Access Databases, Front. Mar. Sci., 6, 1-13, https://doi.org/10.3389/fmars.2019.00019, 2019.

Buck, J. J. H., Bainbridge, S. J., Burger, E. F., Kraberg, A. C., Casari, M., Casey, K. S., Darroch, L., Rio, J. Del, Metfies, K., Delory, E., Fischer, P. F., Gardner, T., Heffernan, R., Jirka, S., Kokkinaki, A., Loebl, M., Buttigieg, P. L., Pearlman, J. S., and Schewe, I.: Ocean Data Product Integration Through InnovationThe Next Level of Data Interoperability, Front. Mar. Sci., 6, https://doi.org/10.3389/fmars.2019.00032, 2019.

Canonico, G., Buttigieg, P. L., Montes, E., Muller-Karger, F. E., Stepien, C., Wright, D., Benson, A., Helmuth, B., Costello, M., Sousa-Pinto, I., Saeedi, H., Newton, J., Appeltans, W., Bednaršek, N., Bodrossy, L., Best, B. D., Brandt, A., Goodwin, K. D., Iken, K., Marques, A. C., Miloslavich, P., Ostrowski, M., Turner, W., Achterberg, E. P., Barry, T., Defeo, O., Bigatti, G., Henry, L. A., Ramiro-Sánchez, B., Durán, P., Morato, T., Murray Roberts, J., García-Alegre, A., Cuadrado, M. S., and Murton, B.: Global observational needs and resources for marine biodiversity, Front. Mar. Sci., 6, 1-20, https://doi.org/10.3389/fmars.2019.00367, 2019.

Crain, C., Halpern, B., Beck, M., and Kappel, C.: Understanding and Managing Human Threats to the Coastal Marine Environment. The Year in Ecology and Conservation Biology, 2009, Ann. NY. Acad. Sci., 1162, 39-62, 2009.

Davidson, F. J., Chassignet, E., Vinayachandran, P. N., Lu, Y., Smith, G. C., Zhu, X., Wang, H., Liu, G., De MeyFrémaux, P., Kourafalou, V., Hernandez, F., Moore, A., Siddorn, J., Martin, M. J., Alvera-Azcárate, A., and Brassington, G.: Synergies in operational oceanography: The intrinsic need for sustained ocean observations, Front. Mar. Sci., 6, 1-18, https://doi.org/10.3389/fmars.2019.00450, 2019. 
DEVOTES: Catalogue of Monitoring Networks, available at: http://www.devotes-project.eu/ devotes-release-new-version-catalogue-monitoring-networks/ (last access: 15 December 2016), 2014.

De Cauwer, V., Ruddick, K., Park, Y., Nechad, B., and Kyramarios, M.: Optical remote sensing in support of eutrophication monitoring in the Southern North Sea, EARSeL eProceedings, 3, 208221, 2004

Duarte, C. M., Poiner, I., and Gunn, J.: Perspectives on a Global Observing System to Assess Ocean Health, Front. Mar. Sci., 5, 265, https://doi.org/10.3389/fmars.2018.00265, 2018.

EC: Directive of 21 May 1991 concerning urban waste water treatment (91/271/EEC)., Off. J. Eur. Communities, L 135, 4052, available at: http://eur-lex.europa.eu/legal-content/EN/ALL/ ?uri=CELEX:31991L0271 (last access: 15 December 2016), 1991a.

EC: Council Directive of 12 December 1991 concerning the protection of waters against pollution caused by nitrates from agricultural sources (91/676/EEC), Off. J. Eur. Communities, L 375, $1-8,1991 b$.

EEA: Europe's Environment - The Dobris Assessment, State of the environment report No 1/1995, available at: http://www.eea. europa.eu/publications/92-826-5409-5 (last access: 20 November 2019), 1995.

EEA: Europe's Environment - The Dobris Assessment, Chapter 35 Coastal Zone Threats and Management, State of the environment report, 6 pp., available at: https://www.eea.europa. eu/publications/92-826-5409-5/page035new.html (last access: 20 November 2019), 2008a.

EEA: Europe's Environment, The Fourth Assessment, Chapter 5 Marine and coastal environment, 44 pp., available at: http: //www.eea.europa.eu/publications/92-826-5409-5 (last access: 20 November 2019), 2008b.

EEA: Europe's environment. An Assessment of Assessments, available at: http://www.eea.europa.eu/themes/regions/ pan-european/sub-regional-assessment-of-assessment-reports/ eastern-europe-assessment-of-assessment-report (last access: 20 November 2019), 2011.

EEA: The European environment - state and outlook 2015: synthesis report, European Environment Agency, Copenhagen, 212 pp., 2015a.

EEA: European Ecosystem Assessment - Concept, Data and Implementation. Technical report No6/2015, 74 pp., 2015 b.

Elliott, M.: Integrated marine science and management: wading through the morass, Mar. Pollut. Bull., 86, 1-4, https://doi.org/10.1016/j.marpolbul.2014.07.026, 2014.

EU: Directive 2000/60/EC of the European Parliament and of the Council of 23 October 2000 establishing a framework for community action in the field of water policy, Off. J. Eur. Communities, 327, 1-72, available at: http://eur-lex.europa. eu/legal-content/EN/TXT/?uri=celex:32000L0060 (last access: 13 November 2019), 2000.

EU: Directive 2008/56/EC of the European Parliament and of the Council of 17 June 2008 establishing a framework for community action in the field of marine environmental policy (Marine Strategy Framework Directive), Off. J. Eur. Union, 164, 1940, available at: http://eur-lex.europa.eu/legal-content/EN/TXT/ ?uri=CELEX:32008L0056 (last access: 13 November 2019), 2008.
EuroGOOS: Sea level observation networks in and around Europe Challenges. in monitoring increasing sea level hazards, Note to policymakers, April, 4 pp., available at: http://eurogoos.eu/download/publications/ EuroGOOS-Tide-Gauge-Note-to-Policy-2017-v.2.pdf （last access: 29 May 2019), 2017.

Farcy, P., Durand, D., Charria, G., Painting, S., Collingridge, K., Gremare, A., Puillat, I., and Delauney, L.: Towards a European Coastal Observing Network to provide better answer to science and to societal challenges; the JERICO Research Infrastructure, Front. Mar. Sci., 6, 1-13, https://doi.org/10.3389/fmars.2019.00529, 2019.

Gabrielsen, P. and Bosch, P.: Environmental Indicators: Typology and Use in Reporting, EEA internal working paper, 2003.

García-García, L., van der Molen, J., Sivyer, D., Devlin, M., Painting, S., and Collingridge, K.: Optimizing monitoring programs: a case study based on the OSPAR Eutrophication assessment for UK waters, Front. Mar. Sci., https://doi.org/10.3389/fmars.2018.00503, 2019.

Grand, M. M., Laes-Huon, A., and Al, E.: Developing autonomous observing systems for micronutrient trace metals, Front. Mar. Sci., https://doi.org/10.3389/fmars.2019.00035, 2019.

Grayek, S., Staneva, J., Schulz-Stellenfleth, J., Petersen, W., and Stanev, E. V.: Use of FerryBox surface temperature and salinity measurements to improve model based state estimates for the German Bight, J. Mar. Syst., 88, 45-59, https://doi.org/10.1016/j.jmarsys.2011.02.020, 2011.

Greenwood, N., Parker, E. R., Fernand, L., Sivyer, D. B., Weston, K., Painting, S. J., Kröger, S., Forster, R. M., Lees, H. E., Mills, D. K., and Laane, R. W. P. M.: Detection of low bottom water oxygen concentrations in the North Sea; implications for monitoring and assessment of ecosystem health, Biogeosciences, 7, 1357-1373, https://doi.org/10.5194/bg-7-1357-2010, 2010.

Grémare, A., Amouroux, J., and Vétion, G.: Long-term comparison of macrobenthos within the soft bottoms of the Bay of Banyulssur-mer (northern Mediterranean Sea), J. Sea Res., 281-302, 1998.

Grémare, A., Durand, D., Delauney, L., Seppala, J., Creach, V. and Farcy, P.: The JERICO-NEXT Science Strategy. JERICO-NEXT-WP1-D1.2-050717-V4.0, available at: http://www.jerico-ri.eu/download/jerico-next-deliverables/ JERICO_NEXT_Deliverable_1.2_Vfinale.pdf (last access: 20 November 2019), 2017.

Groom, S. B., Sathyendranath, S., Ban, Y., Bernard, S., Brewin, B., Brotas, V., Brockmann, C., Chauhan, P., Choi, J. K., Chuprin, A., Ciavatta, S., Cipollini, P., Donlon, C., Franz, B. A., He, X., Hirata, T., Jackson, T., Kampel, M., Krasemann, H., Lavender, S. J., Pardo-Martinez, S., Melin, F., Platt, T., Santoleri, R., Skakala, J., Schaeffer, B., Smith, M., Steinmetz, F., Valente, A., and Wang, M.: Satellite ocean colour: Current status and future perspective, Front. Mar. Sci., 6, https://doi.org/10.3389/fmars.2019.00485, 2019.

Halpern, B., Walbridge, S., Selkoe, K., Kappel, C., Micheli, F., D’Agrosa, C., Bruno, J., Casey, K., Ebert, C., Fox, H., Fujita, R., Heinemann, D., Lenihan, H., Madin, E., Perry, M., Selig, E., Spalding, M., Steneck, R., and R, W.: A global map of human impact on marine ecosystems, Science, 319, 948-952, 2008.

HELCOM: Baltic Marine Environment Protection Commission Baltic Sea Environment Proceedings 155 
Baltic Sea-Second HELCOM holistic, available at: https://www.helcom.fi/baltic-sea-trends/holistic-assessments/ state-of-the-baltic-sea-2018/reports-and-materials/ (last access: 10 March 2019), 2018.

Labrune, C., Grémare, A., Guizien, K., and Amouroux, J.: Longterm comparison of soft bottom macrobenthos in the Bay of Banyuls-sur-Mer (north-western Mediterranean Sea): A reappraisal, J. Sea Res., 58, 125-143, 2007.

Maximenko, N., Corradi, P., Law, K. L., Sebille, E. Van, Garaba, S. P., Lampitt, R. S., Galgani, F., Martinez-Vicente, V., GoddijnMurphy, L., Veiga, J. M., Thompson, R. C., Maes, C., Moller, D., Löscher, C. R., Addamo, A. M., Lamson, M., Centurioni, L. R., Posth, N., Lumpkin, R., Vinci, M., Martins, A. M., Pieper, C. D., Isobe, A., Hanke, G., Edwards, M., Chubarenko, I. P., Rodriguez, E., Aliani, S., Arias, M., Asner, G. P., Brosich, A., Carlton, J. T., Chao, Y., Cook, A. M., Cundy, A., Galloway, T. S., Giorgetti, A., Goni, G. J., Guichoux, Y., Hardesty, B. D., Holdsworth, N., Lebreton, L., Leslie, H. A., Macadam-Somer, I., Mace, T., Manuel, M., Marsh, R., Martinez, E., Mayor, D., Le Moigne, M., Jack, M. E. M., Mowlem, M. C., Obbard, R. W., Pabortsava, K., Robberson, B., Rotaru, A. E., Spedicato, M. T., Thiel, M., Turra, A., and Wilcox, C.: Towards the integrated marine debris observing system, Front. Mar. Sci., 6, https://doi.org/10.3389/fmars.2019.00447, 2019.

Míguez, B. M., Novellino, A., Vinci, M., Claus, S., Calewaert, J. B., Vallius, H., Schmitt, T., Pititto, A., Giorgetti, A., Askew, N., Iona, S., Schaap, D., Pinardi, N., Harpham, Q., Kater, B. J., Populus, J., She, J., Palazov, A. V., McMeel, O., Oset, P., Lear, D., Manzella, G. M. R., Gorringe, P., Simoncelli, S., Larkin, K., Holdsworth, N., Arvanitidis, C. D., Jack, M. E. M., Chaves Montero, M. del M., Herman, P. M. J., and Hernandez, F.: The European Marine Observation and Data Network (EMODnet): Visions and roles of the gateway to marine data in Europe, Front. Mar. Sci., 6, 1-24, https://doi.org/10.3389/fmars.2019.00313, 2019.

Mills, D. K., Greenwood, N., Kröger, S., Devlin, M., Sivyer, D. B., Pearce, D., and Malcolm, S. J.: New Approaches to Improve the Detection of Eutrophication in UK Coastal Waters, Environ. Res. Eng. Manag., 2, 36-42, 2005.

Oesterwind, D., Rau, A., and Zaiko, A.: Drivers and pressures - Untangling the terms commonly used in marine science and policy, J. Environ. Manage., 181, 8-15, https://doi.org/10.1016/j.jenvman.2016.05.058, 2016.

OSPAR: Eutrophication Status of the OSPAR Maritime Area Third Integrated Report on the Eutrophication Status of the OSPAR Maritime Area Eutrophication Series, available at: https://www.ospar.org/work-areas/hasec/eutrophication/ common-procedure (last access: 2 December 2019), 2017.

Proctor, R. and Howarth, M. J.: Coastal observatories and operational oceanography: a European perspective, Mar. Technol. Soc. J., 43, 10-13, https://doi.org/10.4031/002533208786842534, 2008.

Petersen, W: FerryBox systems: State-of-the-art in Europe and future development, J. Mar. Syst., 140, 4-12, 2014.

Schmidt, J. O., Bograd, S. J., Arrizabalaga, H., Azevedo, J. L., Barbeaux, S. J., Barth, J. A., Boyer, T., Brodie, S., Cárdenas, J. J., Cross, S., Druon, J. N., Fransson, A., Hartog, J., Hazen, E. L., Hobday, A., Jacox, M., Karstensen, J., Kupschus, S., Lopez, J., Madureira, L. A. S. P., Martinelli Filho, J. E., Miloslavich, P., Santos, C. P., Scales, K., Speich, S., Sullivan, M. B., Szo- boszlai, A., Tommasi, D., Wallace, D., Zador, S., and Zawislak, P. A.: Future Ocean Observations to Connect Climate, Fisheries and Marine Ecosystems, Front. Mar. Sci., 6, 1-18, https://doi.org/10.3389/fmars.2019.00550, 2019.

Schofield, O., Bergmann, T., Bissett, P., Grassle, J. F., Haidvogel, D. B., Kohut, J., Moline, M., and Glenn, S. M.: The LongTerm Ecosystem Observatory: An Integrated Coastal Observatory, IEEE J. Oceanic. Eng., 27, 146-154, 2002.

Schofield, O., Glenn, S., Bissett, P. W., Frazer, T. K., IglesiasRodriguez, D., and Moline, M. A.: Development of Regional Coastal Ocean Observatories and the Potential Benefits to Marine Sanctuaries, Mar. Technol. Soc. J., 37, 54-67, https://doi.org/10.4031/002533203787537456, 2003.

She, J., Piniella, Á. M., Benedetti-Cecchi, L., Boehme, L., Boero, F., Christensen, A., Crowe, T., Darecki, M., Nogueira, E., Gremare, A., Hernandez, F., Kouts, T., Kromkamp, J., Petihakis, G., Pinto, I. S., Reissmann, J. H., Tuomi, L., and Zingon E. A.: An integrated approach to coastal and biological observations, Front. Mar. Sci., 6, 1-6, https://doi.org/10.3389/fmars.2019.00314, 2019

Smith, L. M., Yarincik, K., Vaccari, L., Kaplan, M. B., Barth, J. A., Cram, G. S., Fram, J. P., Harrington, M., Kawka, O. E., Kelley, D. S., Matthias, P., Newhall, K., Palanza, M., Plueddemann, A. J., Vardaro, M. F., White, S. N., and Weller, R. A.: Lessons Learned From the United States Ocean Observatories Initiative, Front. Mar. Sci., 5, 1-7, https://doi.org/10.3389/fmars.2018.00494, 2019a.

Smith, N., Kessler, W. S., Cravatte, S., Sprintall, J., Wijffels, S., Cronin, M. F., Sutton, A., Serra, Y. L., Dewitte, B., Strutton, P. G., Hill, K., Sen Gupta, A., Lin, X., Takahashi, K., Chen, D., and Brunner, S.: Tropical Pacific Observing Systems, Front. Mar. Sci., 6, https://doi.org/10.3389/fmars.2019.00031, 2019b.

Stammer, D., Bracco, A., AchutaRao, K., Beal, L., Bindoff, N., Braconnot, P., Cai, W., Chen, D., Collins, M., Danabasoglu, G., Dewitte, B., Farneti, R., Fox-Kemper, B., Fyfe, J., Griffies, S., Jayne, S. R., Lazar, A., Lengaigne, M., Lin, X., Marsland, S., Minobe, S., Monteiro, P., Robinson, W., Koll, R. M., Rykaczewski, R., Speich, S., Smith, I., Solomon, A., Storto, A., Takahashi, K., Tonazzo, T., and Vialard, J.: Ocean climate observing requirements in support of Climate Research and Climate Information, Front. Mar. Sci., 6, 1-18, https://doi.org/10.3389/fmars.2019.00444, 2019.

Tanhua, T., Pouliquen, S., Hausman, J., O’Brien, K. M., Bricher, P., Bruin, T. de, Buck, J. J., Burger, E. F., Carval, T., Casey, K. S., Diggs, S., Giorgetti, A., Glaves, H., Harscoat, V., Kinkade, D., Muelbert, J. H., Novellino, A., Pfeil, B. G., Pulsifer, P., Van de Putte, A. P., Robinson, E., Shaap, D., Smirnov, A., Smith, N., Snowden, D. P., Spears, T., Stall, S., Tacoma, M., Thijsse, P., Tronstad, S., Vandenberghe, T., Wengren, M., Wyborn, L., and Zhao, Z.: Ocean FAIR data services, Front. Mar. Sci., 6, https://doi.org/10.3389/fmars.2019.00440, 2019.

Tett, P., Gowen, R., Painting, S., Elliott, M., Forster, R., Mills, D., Bresnan, E., Capuzzo, E., Fernandes, T., Foden, J., Geider, R., Gilpin, L., Huxham, M., McQuatters-Gollop, A., Malcolm, S., Saux-Picart, S., Platt, T., Racault, M.-F., Sathyendranath, S., van der Molen, J., and Wilkinson, M.: Framework for understanding marine ecosystem health, Mar, Ecol.-Prog. Ser., 494, 1-27, https://doi.org/10.3354/meps10539, 2013. 
van Leeuwen, S., Tett, P., Mills, D., and van der Molen, J.: Stratified and non-stratified areas in the North Sea: Long-term variability and biological and policy implications, J. Geophys. Res.-Ocean., 120, 4670-4686, https://doi.org/10.1002/2014JC010485, 2015.

Wang, Z. A., Moustahfid, H., Mueller, A. V., Michel, A. P. M., Mowlem, M., Glazer, B. T., Mooney, T. A., Michaels, W., McQuillan, J. S., Robidart, J. C., Churchill, J., Sourisseau, M., Daniel, A., Schaap, A., Monk, S., Friedman, K., and Brehmer, P.: Advancing Observation of Ocean Biogeochemistry, Biology, and Ecosystems With Cost-Effective in situ Sensing Technologies, Front. Mar. Sci., 6, 1-22, https://doi.org/10.3389/fmars.2019.00519, 2019.
Weller, R. A., Baker, D. J., Glackin, M. M., Roberts, S. J., Schmitt, R. W., Twigg, E. S., and Vimont, D. J.: The challenge of sustaining ocean observations, Front. Mar. Sci., 6, 1-18, https://doi.org/10.3389/fmars.2019.00105, 2019.

Wordle: Viewed 07/06/2018, available at: https://worditout.com/ word-cloud/create (last access: 2 December 2019), 2018.

Zampoukas, N., Piha, H., Bigagli, E., Hoepffner, N., Hanke, G., and Cardoso, A. C.: Marine monitoring in the European Union: How to fulfill the requirements for the marine strategy framework directive in an efficient and integrated way, Mar. Policy, 39, 349351, https://doi.org/10.1016/j.marpol.2012.12.004, 2013. 